\title{
The changing landscape of cervical screening - what does the future hold for primary care?
}

\author{
Laura Marlow \& Jo Waller
}

Department of Behavioural Science and Health, Institute of Epidemiology \& Health Care, UCL, Gower Street, London WC1E 6BT

\begin{abstract}
The landscape of cervical cancer prevention is changing in many countries thanks to the introduction of vaccination against high-risk types of human papillomavirus (HPV) and the incorporation of HPV DNA testing into cervical screening algorithms. In addition to this, uptake of screening is falling year on year in the UK and elsewhere. These factors present challenges and opportunities for health professionals working in primary care - in terms of communicating programmatic changes to women; responding to questions about the meaning and implications of HPV test results; and delivering interventions to increase screening uptake.
\end{abstract}

\section{Background}

In the early nineteen-sixties many believed that a population screening programme offering Papanicolaou (Pap) tests to all women could eliminate invasive carcinoma of the cervix (Bryder, 2008; Boyes, Fidler, \& Lock, 1962). It was another 25 years before the UK introduced its national cervical screening programme, which has indeed had a huge public health impact with reductions in cervical cancer incidence and mortality (Peto, Gilham, Fletcher, \& Matthews 2004), a finding mirrored by many high income countries (Vaccarella, Lortet-Tieulent, Plummer, Franceschi, \& Bray 2013). There is no doubt that we have come a long way since the Papanicolaou test was first described with such optimism, but even countries with well-established screening programmes and high-level quality assurance still have the potential to further reduce cervical cancer mortality (Landy, Pesola, Castanon, \& Sasieni 2016) and it consequently remains on the public health radar. The cervical screening landscape has changed dramatically over the last decade, with the introduction of human papillomavirus (HPV) vaccination and new opportunities for screening using HPV testing alongside cytology (Lorincz, Castanon, Lim, \& Sasieni 2013). These approaches have, and will, continue to have implications for healthcare professionals in primary care. We offer an overview of the current cervical cancer prevention landscape and discuss the possible implications that future changes will have for primary care professionals.

\section{Primary prevention}


The discovery of HPV as the viral precursor that causes pre-cancerous cervical cell changes led to development of vaccinations that can prevent the process from ever beginning. HPV vaccination has been routinely offered in England since 2008 and most Western European countries now offer it for females in early adolescence (Bonanni et al. 2011). The introduction of HPV vaccination has huge implications for the future of the cervical screening programme. Ultimately the numbers of precancerous cervical lesions are expected to decline (Brotherton, Gertig, May, Chappell, \& Saville 2016; Pollock et al. 2014) with far fewer women needing referral for colposcopy and treatment.

Many early media reports suggested that HPV vaccination could mean an end to cervical screening (Hilton, Hunt, Langan, Bedford, \& Petticrew 2010), yet this is unlikely to be the case; there are several reasons for this. Firstly, the HPV vaccinations primarily used in most countries currently only protect against HPV types 16 and 18, which cause around 70\% of cervical cancers in Europe (Munoz et al. 2004). This means that even vaccinated women are likely to need some screening to ensure cell changes caused by the remaining high-risk HPV types are picked up before becoming cancerous. An alternative vaccination which protects against nine HPV types has now been approved by the US Food and Drug Administration and the European Medicines Agency (Lopalco 2017), and estimates suggest this could protect against over $90 \%$ of cervical cancers (Joura et al. 2015), but there are as yet no plans to use this vaccination in the UK. Secondly, even among vaccinated cohorts, there remain unvaccinated women who will be at higher risk of cervical cancer and for whom screening will be particularly important. Thirdly, women in the pre-vaccine era (i.e. born before September 1990 in England) will continue to need screening as currently recommended, until the age of 64 years. With the youngest of these women in their late 20 s, this means cervical screening will remain a dominant part of the cervical cancer prevention strategy for at least another 30 years. Healthcare professionals in primary care who take cervical screening samples will therefore be an important part of this process for the remainder of their careers.

The first routine cohort of girls vaccinated against HPV will enter the screening programme in the UK in 2021 , but women who were in the catch-up programme for vaccination (who were 17-18 years in 2008) are now reaching screening age. While cervical screening will remain important for all women, the interplay between an individual woman's vaccination status and her screening participation will contribute to her cervical cancer risk profile (Wentzensen et al. 2016). Primary care has a key role to play in ensuring that both vaccinated and unvaccinated women understand the potential benefits of screening. Evidence from Wales, Scotland and the Netherlands (Beer et al. 2014;Palmer et al. 2016; Herweijer et al. 2015) suggests that unvaccinated women are also less likely to attend for screening, creating a group of women at disproportionate risk of cervical cancer. Targeting 
unvaccinated women with interventions designed to increase informed participation in screening may become an important focus of cervical cancer prevention.

\section{A new era for cervical screening}

Alongside the development of HPV vaccines, the last decade has seen extensive work exploring the potential benefits of using HPV DNA testing alongside cytology within established cervical screening programmes (Wentzensen et al. 2016). Changes are now underway to move to primary HPV testing in several countries. Primary HPV screening involves testing the cervical sample for high-risk HPV DNA initially. Women with no high-risk HPV infection are returned to routine screening, while those who test positive for the virus have reflexive cytology carried out on the residual sample. If no cytological abnormality is found, they are recalled for repeat HPV testing sooner than the routine screening interval; those with abnormal cytology are referred for colposcopy. The Netherlands was the first to introduce this in 2016 (RIVM 2017) and changes are scheduled for 2017 in Australia (Australian Government Department of Health 2017) and 2019 in England (PHE Screening 2016). Using HPV testing as the primary screening tool has several benefits over cytology including increased test sensitivity and the potential to lengthen screening intervals for women with a negative HPV result (Dijkstra et al. 2016;Lorincz et al. 2013). In general, HPV is still unfamiliar to many people and while written information about changes to the screening programme will be developed (in leaflets and online) health professionals are likely to be a key source of information; helping to inform women about what these changes mean. There is therefore an urgent need to ensure that primary care staff are adequately trained to communicate with women about these changes, as previous research has shown that discussions about HPV can be seen as a 'can of worms' (McSherry et al. 2012). One approach is the development of scripted consultations to help clinicians in these conversations (Hendry et al. 2016).

Good communication about HPV testing in primary care is essential both to ensure informed choice when screening is being delivered, but also to ensure that if women are confused about their results, they can receive good information from their primary care provider. Primary HPV testing will identify, for the first time, a group of women who test positive for the virus in the absence of any cytological abnormalities. Little is known about how these women will make sense of their results; whether they will be anxious about their cancer risk, concerned with the sexually transmitted nature of the infection, or insufficiently concerned to attend for early recall (McBride et al. 2016). Primary care staff will have a key role in ensuring that these women received clear and consistent information.

\section{Ensuring engagement}


The introduction of HPV vaccination and the move to primary HPV testing have been at the forefront of discussions about cervical cancer prevention over the last ten years. In the background however the same time frame has seen a steady decline in coverage of cervical screening in England, with the exception of a blip in this trend following the death of a UK celebrity, Jade Goody in 2009 (Lancucki, Sasieni, Patnick, Day, \& Vessey 2012). Coverage is lowest among the youngest women invited and also slightly lower than average in the oldest age groups (Screening and Immunisations Team 2016). Other developed countries have seen similar declines in attendance among young women (Lancucki et al. 2010). Reasons for reduced engagement are unclear but it may, in part, be that screening is a victim of its own success with falling rates of cervical cancer meaning fewer women are aware of it through personal experience of relatives or friends. If this is the case, the success of the vaccine may well exacerbate this further. The short-term impact of Jade Goody's diagnosis with cervical cancer on screening uptake (Lancucki et al., 2012) suggests that increasing the immediate salience of the disease might prompt screening engagement.

Novel ways are needed to encourage women to attend screening. Publication of the recent STRATEGIC trial showed evidence that timed appointments improved attendance among nonattenders following their first invitation for screening (Kitchener et al. 2016). It is likely that mobile technology can be harnessed to increase participation, through easier booking of appointments, and text message or email reminders (e.g. Huf 2016). In addition, the use of self-sampling for HPV testing is generally acceptable (Nelson et al. 2017) and shows great promise for increasing uptake in women who are overdue as well as those who have never attended (Sultana et al. 2016;Albrow et al. 2014). HPV self-sampling will become more feasible in the UK and elsewhere once HPV primary screening is introduced and could be particularly useful for those who are concerned about the speculum or cannot attend appointments. This type of targeted intervention could be part of a broader trend to personalise screening information - something that primary care could be well-placed to deliver. It is increasingly clear that screening non-participants are a heterogeneous group, with multiple different reasons for not taking part. These range from lack of awareness of the screening programme through to positive intentions to take part, hampered only by competing demands on their time, or difficult appointment systems (Chorley, Marlow, Forster, Haddrell, \& Waller 2016). A one-size-fits-all approach to increasing screening uptake is unlikely to be effective - indeed the only intervention that has consistently been shown to be effective is the use of invitations and reminders, something already done within organised programmes and many primary care practices (Everett et al. 2011). For those women who do not respond to any population-based interventions (e.g. reminders, online booking, mailed self-test kits), the only opportunity to engage them in considering cervical screening may be opportunistically, when attending primary care for another reason. A 
recent study showed that around $60 \%$ of screening non-attenders in East London had attended a primary care appointment in the last year (Lim \& Sasieni 2015), suggesting opportunistic approaches may be feasible.

\section{Conclusions}

Cervical cancer prevention is entering a period of change in many European countries, during which health professionals working in primary care will play a key role in delivering services and communicating with women. With continued high coverage of HPV vaccination and ever improving screening tests, the goal of eradicating cervical cancer in many high-income countries is now closer than ever. It is important to remember, though, that over $85 \%$ of cervical cancer deaths occur in low and middle income countries (Samarasekera \& Horton 2016), so an important future priority must be to implement primary and secondary prevention strategies into the countries where the need is greatest. Primary care professionals will likely face questions and confusion about future changes. Proposals to change screening, particularly when it involves taking something away (i.e. reducing the age-range of those eligible for screening or lengthening the screening interval), is often perceived negatively by the public. In Australia for example, the proposed changes to cervical screening have resulted in public backlash with over 70,000 people signing a petition against the proposed changed (change.org, 2017). Primary care professionals should ensure they are able to clearly articulate why changes are being made and the benefits they will bring (The Conversation, 2017). This will help to ensure clear consistent messages are communicated in a way that maintains public confidence in screening.

\section{Funding}

Both authors are supported by a Cancer Research UK career development fellowship awarded to $\mathrm{Dr}$ Waller (C7492/A17219) 


\section{References}

Albrow R., Blomberg K., Kitchener H., Brabin L., Patnick J., Tishelman C., Tornberg S., Sparen P., \& Widmark C. (2014) Interventions to improve cervical cancer screening uptake amongst young women: a systematic review. Acta Oncologica, 53, 445-451.

Australian Government Department of Health. (2017) Future changes to cervical screening. Available at: http://www.cancerscreening.gov.au/internet/screening/publishing.nsf/content/future-changescervical [accessed on 16 March 2017].

Beer H., Hibbitts S., Brophy S., Rahman M.A., Waller J., \& Paranjothy S. (2014) Does the HPV vaccination programme have implications for cervical screening programmes in the UK? Vaccine, 32, 1828-1833.

Bonanni P., Levi M., Latham N.B., Bechini A., Tiscione E., Lai P., Panatto D., Gasparini R., \& Boccalini S. (2011) An overview on the implementation of HPV vaccination in Europe. HumanVaccines, 7 Suppl, 128-135.

Boyes D.A., Fidler H.K., \& Lock D.R. (1962) Significance of in situ carcinoma of the uterine cervix. British Medical Journal, 1, 203-205.

Brotherton J.M., Gertig D.M., May C., Chappell G., \& Saville M. (2016) HPV vaccine impact in Australian women: ready for an HPV-based screening program. The Medical Journal of Australia, $204,184-184 \mathrm{e} 1$.

Bryder L. (2008) Debates about cervical screening: an historical overview. Journal of Epidemiology and Community Health 62, 284-287.

Change.org. (2017) https://www.change.org/p/malcolm-turnbull-stop-may-1st-changes-to-papsmears-save-women-s-lives?source_location=minibar [accessed on 16 March 2017].

Chorley A.J., Marlow L.A., Forster A.S., Haddrell J.B., \& Waller J. (2017) Experiences of cervical screening and barriers to participation in the context of an organised programme: a systematic review and thematic synthesis. Psychooncology, 26, 161-172.

Dijkstra M.G., van Z.M., Rozendaal L., van Kemenade F.J., Helmerhorst T.J., Snijders P.J., Meijer C.J., \& Berkhof J. (2016) Safety of extending screening intervals beyond five years in cervical screening programmes with testing for high risk human papillomavirus: 14 year follow-up of population based randomised cohort in the Netherlands. BMJ 355, i4924. 
Everett T., Bryant A., Griffin M.F., Martin-Hirsch P.P., Forbes C.A., \& Jepson R.G. (2011) Interventions targeted at women to encourage the uptake of cervical screening. Cochrane Database of Systematic.Reviews, 11, CD002834.

Hendry M., Pasterfield D., Adams R., Evans M., Fiander A., Robling M., Campbell C., Makin M., Gollins S., Hiscock J., Nafees S., Bekkers M.J., Rose J., Williams O., Stanley M., \& Wilkinson C. (2016) Talking about human papillomavirus and cancer: protocol for a patient-centred study to develop scripted consultations. BMJ Open. 6, e011205.

Herweijer E., Feldman A.L., Ploner A., Arnheim-Dahlstrom L., Uhnoo I., Netterlid E., Dillner J., Sparen P., \& Sundstrom K. (2015) The Participation of HPV-Vaccinated Women in a National Cervical Screening Program: Population-Based Cohort Study. PLoS One 10, e0134185.

Hilton S., Hunt K., Langan M., Bedford H., \& Petticrew M. (2010) Newsprint media representations of the introduction of the HPV vaccination programme for cervical cancer prevention in the UK (20052008). Social Science and Medicine, 70, 942-950.

Huf S (2016). Can Text Reminders Improve Uptake of Cervical Screening? Available at: https://clinicaltrials.gov/ct2/show/NCT02363088 [accessed on 23 January 2017].

Joura E.A., Giuliano A.R., Iversen O.E., Bouchard C., Mao C., Mehlsen J., Moreira E.D., Jr., Ngan Y., Petersen L.K., Lazcano-Ponce E., Pitisuttithum P., Restrepo J.A., Stuart G., Woelber L., Yang Y.C., Cuzick J., Garland S.M., Huh W., Kjaer S.K., Bautista O.M., Chan I.S., Chen J., Gesser R., Moeller E., Ritter M., Vuocolo S., \& Luxembourg A. (2015) A 9-valent HPV vaccine against infection and intraepithelial neoplasia in women. New England Journal of Medicine, 372, 711-723.

Kitchener H.C., Gittins M., Rivero-Arias O., Tsiachristas A., Cruickshank M., Gray A., Brabin L., Torgerson D., Crosbie E.J., Sargent A., \& Roberts C. (2016) A cluster randomised trial of strategies to increase cervical screening uptake at first invitation (STRATEGIC). Health Technology Assessment, 20, 1-138.

Lancucki L., Fender M., Koukari A., Lynge E., Mai V., Mancini E., Onysko J., Ronco G., Tornberg S., Vessey M., \& Patnick J. (2010) A fall-off in cervical screening coverage of younger women in developed countries. Journal of Medical Screening, 17, 91-96.

Lancucki L., Sasieni P., Patnick J., Day T.J., \& Vessey M.P. (2012) The impact of Jade Goody's diagnosis and death on the NHS Cervical Screening Programme. Journal of Medical Screening, 19, 89-93. 
Landy R., Pesola F., Castanon A., \& Sasieni P. (2016) Impact of cervical screening on cervical cancer mortality: estimation using stage-specific results from a nested case-control study. British Journal of Cancer 115, 1140-1146.

Lim A.W. \& Sasieni P. (2015) Consultation rates in cervical screening non-attenders: opportunities to increase screening uptake in GP primary care. Journal of Medical Screening, 22, 93-99.

Lopalco P.L. (2017) Spotlight on the 9-valent HPV vaccine. Drug Design, Development and Therapy, $11,35-44$.

Lorincz A., Castanon A., Lim A.W., \& Sasieni P. (2013) New strategies for human papillomavirusbased cervical screening. Womens Health (London), 9, 443-452.

McBride E., Marlow L., Forster A.S., Moss S., Myles J., Kitchener H., Patnick J., \& Waller J. (2016) Psychological Impact of Primary Screening (PIPS) for HPV: a protocol for a cross-sectional evaluation within the NHS cervical screening programme. BMJ Open, 6, e014356.

McSherry L.A., Dombrowski S.U., Francis J.J., Murphy J., Martin C.M., O'Leary J.J., \& Sharp L. (2012) 'It's a can of worms': understanding primary care practitioners' behaviours in relation to HPV using the Theoretical Domains Framework. Implementation Science, 7, 73.

Munoz N., Bosch F.X., Castellsague X., Diaz M., de S.S., Hammouda D., Shah K.V., \& Meijer C.J. (2004) Against which human papillomavirus types shall we vaccinate and screen? The international perspective. International Journal of Cancer, 111, 278-285.

Nelson E.J., Maynard B.R., Loux T., Fatla J., Gordon R., \& Arnold L.D. (2017) The acceptability of selfsampled screening for HPV DNA: a systematic review and meta-analysis. Sexually Transmitted Infections, 93, 56-61.

Palmer T.J., McFadden M., Pollock K.G., Kavanagh K., Cuschieri K., Cruickshank M., Nicoll S., \& Robertson C. (2016) HPV immunisation and increased uptake of cervical screening in Scottish women; observational study of routinely collected national data. British Journal of Cancer, 114, 576581.

Peto J., Gilham C., Fletcher O., \& Matthews F.E. (2004) The cervical cancer epidemic that screening has prevented in the UK. Lancet, 364, 249-256.

PHE Screening. (2016) HPV primary screening in the cervical screening programme. Available at: https://phescreening.blog.gov.uk/2016/04/13/hpv-primary-screening-in-the-cervical-screeningprogramme/ [accessed on 23 January 2017]. 
Pollock K.G., Kavanagh K., Potts A., Love J., Cuschieri K., Cubie H., Robertson C., Cruickshank M., Palmer T.J., Nicoll S., \& Donaghy M. (2014) Reduction of low- and high-grade cervical abnormalities associated with high uptake of the HPV bivalent vaccine in Scotland. British Journal of Cancer, 111, 1824-1830.

RIVM. (2017) Cervical cancer screening in the Netherlands. Available at:

http://www.rivm.nl/en/Documents_and_publications/Common_and_Present/Newsmessages/2014/ Cervical_cancer_screening_in_the_Netherlands [accessed on 23 January 2017].

Samarasekera U. \& Horton R. (2016) Women's cancers: shining a light on a neglected health inequity. Lancet, in press.

Screening and Immunisations Team, NHS Digital. (2016) Cervical Screening Programme, England: Statistics for 2015-16. Available at: http://www.content.digital.nhs.uk/catalogue/PUB22414/nhscerv-scre-prog-eng-2015-16-rep.pdf [accessed on 23 January 2017].

Sultana F., English D.R., Simpson J.A., Drennan K.T., Mullins R., Brotherton J.M., Wrede C.D., Heley S., Saville M., \& Gertig D.M. (2016) Home-based HPV self-sampling improves participation by neverscreened and under-screened women: Results from a large randomized trial (iPap) in Australia. International Journal of Cancer, 139, 281-290.

The Conversation (2017) http://theconversation.com/five-myths-about-the-new-cervical-screeningprogram-that-refuse-to-die-74077_[accessed on 23 January 2017].

Vaccarella S., Lortet-Tieulent J., Plummer M., Franceschi S., \& Bray F. (2013) Worldwide trends in cervical cancer incidence: impact of screening against changes in disease risk factors. European Journal of Cancer 49, 3262-3273.

Wentzensen N., Arbyn M., Berkhof J., Bower M., Canfell K., Einstein M., Farley C., Monsonego J., \& Franceschi S. (2016) Eurogin 2016 Roadmap: How HPV knowledge is changing screening practice. International Journal Cancer, in press. 